\title{
Surdez e preconceito: a norma da fala e o mito da leitura da palavra falada
}

\author{
Sílvia Andreis Witkoski
}

Universidade Federal do Paraná, Programa de Pós-Graduação em Educação

\section{Introdução}

Falar sobre surdez e preconceito é narrar uma das interfaces do ser surdo. Na história do povo surdo estão evidentes as marcas que o identificam como um ser incompleto, incapaz, deficiente. A partir dessa concepção da surdez, todo tipo de violência física e simbólica foi exercida, passando por extermínio, reclusão em casa, proibição do uso da língua de sinais, segregação em escolas especiais, até as atuais propostas pedagógicas adjetivadas como bilíngues, utilizadas “como mais uma metodologia colonialista, a-histórica e despolitizada"; que consistem em apenas permitir o uso da língua de sinais sem empreender qualquer ação no sentido de transformar as relações sociais, culturais e institucionais (Sá, 2002, p. 358).

Dentre o imenso leque de preconceitos que envolvem o ser surdo, este texto pretende discutir a norma da fala e o mito da leitura da palavra falada, por entender o quanto ambos legitimam uma série de práticas oralistas ${ }^{1}$, afetando de forma pejorativa

${ }^{1}$ Práticas oralistas constituem-se na forma institucionalizada do ouvintismo. Os termos ouvintista, ouvintismo etc. são derivações a construção da identidade do ser surdo e seu direito a uma comunicação e formação significativa. Nesse sentido, vale ressaltar que "a comunicação via fala e leitura de lábios da língua falada é necessariamente muito limitada para uma pessoa que não pode ouvir. Portanto, a fala pode representar apenas funções comunicativas muito básicas para os surdos” (Svartholm, 1999, p. 19).

No entanto, ambos implicam a oralização dos surdos e intermináveis exercícios de treinamento, em detrimento da formação acadêmica. Ao implicitamente não aceitar a diferença linguística, de percepção do mundo e forma de ser, essas práticas mascaram os preconceitos. Elas promovem uma pseudoinviabilização da surdez, realizada com o argumento de uma pretensa integração entre surdos e ouvintes.

Antes de qualquer coisa, considero ser importante esclarecer de que lugar eu estou falando, pois certa-

de “ouvintização”, que, segundo a concepção de Skliar (1999, p. 7), sugere "uma forma particular e específica de colonização dos ouvintes sobre os surdos. Supõe representações práticas de significação, dispositivos pedagógicos etc. em que os surdos são vistos como sujeitos inferiores”. 
mente o fato de ser surda implica a construção de um texto em que fica evidente a repulsa por todo tipo de preconceito que busca nos aprisionar nos discursos do ouvintismo, levando-nos muitas vezes a desenvolver a sua face mais perversa, que é contra nós próprios, assimilando-os como se fossem verdades. Em vários momentos farei uso inclusive de minha própria experiência em face dos preconceitos, para que, pelo exemplo de fatos narrados pelos próprios surdos, possa trazer à tona suas nuanças, desvelar alguns dos discursos que os legitimam e desnudar as implicações dolorosas que geram na vida dos surdos.

\section{A norma da fala}

Machado (2008, p. 24) observa que a maioria das escolas regulares com alunos surdos adere à abordagem oralista, não aventando outras perspectivas. Segundo o autor, "parece haver um consenso mudo, por exemplo, sobre o fato de que, se todos falam, esse estudante deve também falar”. Obviamente, falar é limitado à concepção ouvinte que a restringe às línguas processadas pelo canal auditivo-oral, não reconhecendo a modalidade visual-motora da língua de sinais como a natural dos surdos. Pode-se afirmar que a linguagem, por convenção, ainda está vinculada à acústica (Wrigley, 1996, p. 11). Nessa perspectiva, “não ter a fala” pressupõe, em uma sociedade oral, a mudez; dito de outro modo: pressupõe "ausência de pensamento ou, pelo menos, pressupõe que o surdo não tem o que dizer” (Lopes, 2007, p. 51).

Essa superioridade da palavra remete à visão aristotélica que a relaciona ao mundo das ideias, da razão, enquanto o mundo concreto e material é representado pelo gesto. Segundo Sacks (1998, p. 28), talvez essa ideia equivocada (ou preconceito) de que os símbolos precisam ser falados "remonte aos tempos bíblicos: o status sub-humano dos surdos era parte do código mosaico e foi reforçado pela exaltação bíblica da voz e do ouvido como o único e verdadeiro modo como o homem e Deus podiam falar (“No princípio, era o Verbo”).

A naturalização desta modalidade de comunicação linguística continua a ser percebida por muitas pessoas como característica que identifica os seres humanos, distinguindo-os dos animais, classificados como irracionais. Tamanha é essa referência que por muito tempo - e ainda hoje, segundo vivências relatadas por amigos surdos -, ao se comunicarem por meio de Libras em um ambiente ocupado predominantemente por ouvintes, seu uso é referido como "coisa de macaco”. Mesmo não tendo passado por situação explícita de discriminação como essa, ao conversar com amigos surdos pela língua de sinais percebo o preconceito em sua versão sutil: nos olhares, no quanto parecemos exóticos, sendo imensamente observados, disfarçadamente.

A questão de a diferença do ser surdo ser percebida pelo foco da deficiência é que perpetua a obstinação em fazer o surdo falar na mesma modalidade do ouvinte, sob a lógica ouvintista e normalizadora, ancorada no argumento de que se o surdo aprender a falar português estará incluído na sociedade, visto que esta é a língua majoritária (no caso do Brasil). Em nome dessa pseudointegração, os surdos são submetidos a intermináveis sessões de treinamento. No entanto, mesmo quando aprende a falar a língua portuguesa, o surdo continua a não ser aceito na comunidade ouvinte, sendo identificado como deficiente, em função do que muitos referem de "o jeito surdo" de falar, em referência à fala truncada, à diferença na pronuncia ou na clareza articulatória das palavras.

Mesmo no caso de surdos que têm uma fala considerada inteiramente compreensível e que fazem uso de um discurso fluente da língua portuguesa (por terem ensurdecido quando já tinham domínio da língua), o preconceito persiste pelo fato de eles não ouvirem ou ouvirem em nível bem abaixo do dos ouvintes. Desse modo, “aquele que não ouve tão bem, ou não percebe algumas manifestações sonoras na medida em que deveria, frequentemente passa a ser distinguido como alguém com perda, com carência, com falta de, com deficiência e como pessoa portadora de uma especificidade" (Lulkin, 1998, p. 40), deficiência identificada pelo não-entendimento das informações faladas, pelo uso da prótese auditiva ou, mesmo na ausência desta, pelo desencontro entre a 
modulação da voz do surdo e a utilizada pelo ouvinte em diferentes contextos conversacionais. Esse desencontro ocorre pelo fato de o surdo não ouvir a sua própria voz ou ouvi-la somente quando ela está em um nível sonoro muito alto em relação aos ouvintes, o que faz com que não consiga monitorar a sua sonoridade com o sentido da audição.

Fazendo uso da minha própria vivência, exemplifico os preconceitos que permanecem mesmo quando o surdo fala português dentro dos padrões convencionais. Minhas filhas estavam brincando no playground do prédio com uma menina que tinha se mudado havia pouco tempo. Ao conversar com sua mãe, sinto dificuldade de entendê-la e me identifico como surda, solicitando que ela olhe para mim quando falar. Pergunto o nome da sua filha, que entendo ser Larissa. Passo a chamá-la assim, inclusive na frente da mãe. Passados alguns dias, a Larissa, que estava brincando novamente com minhas filhas, ao terminar um desenho assina: Raíssa. Opa! Por que a mãe da criança não me corrigiu? A resposta é evidente: o preconceito que nos identifica como deficientes, como coitadinhos, imperou!

Nesse sentido, dizer que se o surdo falar português estará integrado à comunidade ouvinte é um grande engodo; ele continuará sendo visto como um deficiente e tratado como tal. Nessa perspectiva, relato outro episódio de preconceito, que para mim simbolizou o quanto eles estão presentes, profundamente enraizados, e são difíceis de ser desconstruídos: em 2008, logo após minha aprovação no processo seletivo para o doutorado em educação da Universidade Federal do Paraná (UFPR), compareci a uma defesa de tese de doutorado na qual eram discutidos alguns elementos sobre a educação dos surdos. Antes de iniciar o evento, fui apresentada à autora do projeto, que, na tentativa de ser simpática, e obviamente nervosa pela característica avaliatória do evento, deixa escapar: "Eu tive uma amiga que teve um problema como o seu (referindo-se ao meu processo de ensurdecimento), foi operada e ficou normal!". De imediato, eu lhe respondi: “Eu sou normal!”. Muito constrangida, ela desculpou-se.
Nesse ato falho, ${ }^{2}$ ficou claro como uma pesquisadora, que, a priori, por seu trabalho inserido na abordagem socioantropológica da surdez, tem um discurso “politicamente correto”, não está plenamente convencida de seus argumentos, mantendo resquícios dos preconceitos de percebê-la a partir do foco da deficiência, e assim inconscientemente sugerir uma possibilidade de cura para um corpo visto com defeito. Indubitavelmente, nessa fala, num lapso inconsciente, ela aventou uma possibilidade de me igualar novamente aos ouvintes, sem se dar conta de que essa pretensa esperança de voltar a ser normal, ${ }^{3}$ segundo sua perspectiva, implicaria descartar minha própria identidade. $\mathrm{Na}$ verdade, de forma inconsciente ela resgatou a base das políticas ouvintistas, que intentam a "cura" da surdez, perpetuando os processos normalizadores, como diz Wrigley (1996, p. 71):

\section{[...] surdos são pessoas que ouvem com ouvidos defeituosos. Se pudéssemos consertar os ouvidos, eles estariam ouvindo. Esta lógica comum na verdade é comum, mas não necessa- riamente lógica. Os negros são pessoas brancas que possuem pele escura. Se pudéssemos consertar a pele, eles seriam brancos. As mulheres são homens com genitália errada..., e por aí vai. Essas transposições cruas revelam um tecido social de práticas pelas quais nós sabemos quais identidades são tanto disponíveis quanto aceitáveis.}

Outra questão fundamental que contradiz essa alusão, ou melhor, ilusão de que se o surdo falar português estará integrado à comunidade ouvinte e que coexiste com a manutenção dos preconceitos referidos, reside no fato de o surdo continuar a ser excluído no

\footnotetext{
2 Os atos falhos, de acordo com a concepção de Freud (1976),
} são ações inconscientes, constituídas por determinados elementos que o sujeito não pretendia enunciar. O seu significado oculto só aparece na hora em que escapa ao controle da repressão.

${ }^{3}$ Como surda, minha concepção de normalidade em relação aos surdos é a mesma defendida pela pesquisadora surda Gladis Perlin, que afirma: "Ser normal segue uma norma. Mas ser normal para o surdo significaria ser surdo, ser autenticamente surdo" (Perlin, 2007, p. 9). 
essencial: o direito de acesso fluente e irrestrito às informações produzidas via língua auditivo-oral, que constitui um direito, um princípio básico de cidadania. Em relação ao processo de discriminação do surdo, que impõe uma marginalização social e cultural, não vejo sequer a necessidade de ilustrar com exemplos, pois estes são tantos - desde a falta de legenda em português ou de tradução em Libras dos programas televisivos e outros similares, ao direito elementar de acesso aos conteúdos de uma aula no ensino regular, pois, ainda na maioria das situações de alunos surdos “incluídos”, o recurso predominante para tal é a leitura da palavra falada - que não bastaria um artigo, mas sim um livro de exclusões diárias.

Outro aspecto importante o qual me sinto plenamente confortável para apontar como grande engodo - visto que durante 35 anos fui uma ouvinte - é a possibilidade de o surdo ser aceito na comunidade ouvinte, desde que fale como um dos seus e tenha um treinamento da leitura da palavra falada impecável; há aí um caráter subliminar acrescentado a essa promessa de integração, como se por via dela viesse a receber o ingresso a um “paraíso ouvinte”. Essa promoção hedonista de um mundo ouvinte que não existe simplifica as relações e possibilidades à materialidade da surdez, escondendo a complexa rede de relações de poder que compõem o tecido social e interferem na vida em sociedade, tanto no caso do ouvinte como do surdo.

É importante ressaltar que ser ouvinte não é sinônimo de ser feliz, ter sucesso e ser aceito entre seus pares, ideia que é vendida aos surdos. Inúmeras são as diferenças socioculturais e as desigualdades presentes também na comunidade ouvinte, na qual coabita uma série de outros preconceitos, a partir dos "marcadores sociais da diferença” (Starling \& Schwarcz, 1989, p. 219), como raça, gênero, sexo, idade e classe.

Vivemos uma realidade nefasta na qual são produzidas imensas injustiças sociais, por conflitos raciais e religiosos, dentre outros, todos governados por uma política de significação na qual impera o que Skliar (2000, p. 11) denominou "modelo econômicopolítico concêntrico”, que promove, através da mídia, uma teoria e uma práxis de globalização a partir de uma pretensa homogeneidade humana inexistente. No entanto, esta se sustenta pelos diferentes preconceitos presentes na sociedade como expressão máxima do etnocentrismo, definida pelo professor João Baptista Borges Pereira como "tendência, ao que tudo indica universal, que leva indivíduos, grupos e povos à supervalorização de suas próprias expressões de vida, conduzindo-os, consequentemente, a subestimar as características de outros indivíduos, grupos e povos" (in Schwarcz, 1989, p. 175). E o tipo ideal, vinculado ao estereótipo da felicidade, corresponde "no mínimo a ser: jovem, do gênero masculino, branco, cristão, heterossexual, física e mentalmente perfeito, belo e produtivo" (Amaral, 1998, p. 14).

Nessa perspectiva, ao se absolutizar a divisão surdo/ouvinte, levando os surdos à miragem dos ouvintes como um paraíso perdido, em primeiro lugar se está criando a ilusão de eles se submeterem às concepções e práticas ouvintistas, em prol de uma realidade inexistente; em segundo, alienando-os em relação a questionar e impor resistência a outros preconceitos presentes no seu cotidiano, como se ser surdo fosse ter uma identidade única. Essa perspectiva que desconsidera de que surdo estamos falando remete ao cerne do preconceito em relação à surdez que nos identifica a partir da deficiência como um grupo homogêneo.

\section{Os limites da leitura da palavra falada}

A famosa leitura labial, ${ }^{4}$ apontada como a possibilidade de o surdo “compensar” o sentido da audição para ter acesso às informações via palavras faladas, é hiperestimada, constituindo-se em um mito. De acordo com Sacks (1998, p. 82), a “leitura labial não é apenas uma habilidade visual - 75\% dela é uma espécie de adivinhação inspirada ou conclusão por hipótese, dependendo do uso de pistas encontradas no contexto". Por sua vez, Shirley Vilhalva (2004, p. 25), autora surda, ao descrever a leitura orofacial, explica a difi-

\footnotetext{
${ }^{4}$ Segundo Sacks (1998, p. 15), “'leitura labial’ é um termo
} bastante inadequado para designar a complexa arte de observação, inferência e adivinhação inspirada dessa tarefa”. 
culdade do processo a partir de dois pontos centrais: a necessidade de conhecer os códigos do falante e a diferença de tempos entre a realização da leitura e o ritmo da fala.

Em relação ao primeiro elemento, a autora argumenta que a criança surda, para compreender uma conversa, busca nos movimentos dos lábios e expressões as palavras-chave que, apesar de serem vagas, num ambiente em que está familiarizada permitem que ela "leia" as intenções das pessoas que a cercam; no entanto, ao mudar o ambiente os códigos também se alteram e o processo fica extremamente prejudicado. Em relação ao segundo aspecto, Vilhalva (2004, p. 26) esclarece que a leitura labial, ao ser realizada por um processo de percepção visual, é mais lenta, e alerta para a diferença entre o ritmo do processo de elaboração mental das palavras e da fala a partir do seguinte exemplo:

“Bom dia! Como vai você? Tudo bem?” E continua falando... O surdo, quando estiver lendo os lábios - “Bom dia! Como vai...”, até ser estruturado o pensamento e compreender a mensagem, já perdeu o restante da frase, e quando volta ler novamente defronta-se com palavras soltas, levando-o assim a tentar adivinhar as palavras desconhecidas num contexto geral.

As dificuldades da leitura da palavra falada não se restringem aos aspectos já mencionados. Fatores como o tipo de articulação do locutor, a proximidade ou distância dele, a importância da perspectiva frontal dos lábios do falante em relação ao surdo (posicionado horizontalmente em relação aos seus olhos), a semelhança articulatória de determinadas letras e o prévio conhecimento das palavras pronunciadas são apenas alguns elementos que interferem no processo e demonstram o quanto a leitura labial é mitificada.

Vale ressaltar que o ambiente de conversação usual não se constitui num ideal de apreensão visual ao surdo; ao contrário. Em geral este é caracterizado pela presença de um falante distante, em permanente movimento (quando não está inclusive ausente do seu foco visual), que realiza trocas verbais com outras pessoas as quais não poderão ser observadas concomitantemente. Estas são as características mais comuns do dialogo entre ouvintes, sendo inclusive também as da sala de aula no ensino regular.

Considerar que o aluno surdo possa ser integrado/ incluído na escola regular a partir da possibilidade de ele realizar leitura orofacial, sem acesso pelo menos a um intérprete em língua de sinais, é no mínimo uma cômoda justificativa ingênua de estar incluindo-o para excluir. Nesse sentido, concordo com Skliar (2000, p. 17) na ideia de que, em relação aos surdos, essas "políticas de integração transformam-se rapidamente em práticas de assimilação ou produzem, como um efeito contrário, maior isolamento e menores possibilidades educativas nessas crianças”. Para tal, basta considerar os numerosos depoimentos dos surdos que expressam a dificuldade de compreensão nesse contexto a partir desse recurso, como pode ser ilustrado pela vivência de dois alunos surdos a seguir:

\footnotetext{
Eu tinha 13 anos quando voltei para a escola de ouvintes. Foi um sufoco. Não entendia nada e ficava isolada, sem conversar com professores e colegas. (Machado, 2008, p. 115) Na sala de aula é muito complicado, o professor explica no quadro pá, pá, pá, pá... O surdo não entende. (idem, ibidem, p. 119)
}

A mesma dificuldade é encontrada inclusive por surdos que fazem uso de aparelho auditivo - uma tecnologia normalizadora ${ }^{5}$ cuja função é recuperar o corpo danificado, dando uma "suposta" equiparação de oportunidades - e podem, a priori, utilizar-se de algum nível de percepção auditiva para a compreensão dos conteúdos das aulas concomitantemente à leitura da palavra falada, como ilustrado no depoimento a seguir:

Passei a maior dificuldade na sala de aula. O uso do aparelho auditivo era muito perturbador, parecia que estava ficando

${ }^{5} \mathrm{O}$ termo tecnologia normalizadora está sendo utilizado segundo a definição: "As tecnologias normalizadoras se exercem produzindo subjetividades e sujeitos normalizados através da interação homem-máquina” (Thoma \& Pellanda, 2006, p. 124). 
louca, muito barulho. Não conseguia entender o que os professores e os alunos conversavam e tinha que suportar o barulho do aparelho. (Machado, 2008, p. 122)

Em relação à dificuldade de acesso às informações pelos surdos que fazem uso do aparelho auditivo - que em princípio se constitui em um facilitador do processo de leitura orofacial -, também pela minha vivência percebo o quanto essa situação é mitificada. Nesse sentido, destaco os transtornos decorrentes da permanente poluição sonora de uma sala de aula - que são um tormento, ainda mais quando acrescidos de ruídos e ecos produzidos pelo próprio aparelho, pelo excesso de barulho ou outros sons ambientais (como a passagem de carros), que atrapalham o raciocínio e, obviamente, a compreensão do que esta sendo falado - e da dependência da familiaridade com o tema e expressões típicas no transcorrer de uma aula. Em relação a esse aspecto, parece-me que há uma grande contradição se considerarmos que o esperado em um processo de ensino-aprendizagem é ampliar as perspectivas e domínios, inclusive promovendo a apropriação de novas terminologias.

Ainda no relato de minha experiência: a impossibilidade de acompanhar os diálogos que transcorrem em sala de aula - até que eu consiga localizar no campo visual quem está falando já perdi metade dos argumentos - esvazia em muito o acesso à qualidade das informações partilhadas. As entrelinhas da troca conversacional sempre pairam no ar! Também ficamos excluídos do aprendizado incidental, proveniente daquele burburinho de conversas que ocorrem durante uma aula e nos corredores das instituições de ensino. Ademais, a situação não oferece conforto linguístico; ao contrário, exaure. Por esse motivo, nas minhas aulas no doutorado conto com uma intérprete em Libras.

Para finalizar este primeiro momento de discussão sobre o mito da leitura labial, uso o depoimento de Karen Strobel (2008a, p. 16), pesquisadora surda e mãe de um lindo menino surdo, que ilustra exemplarmente o processo discriminatório alicerçado na conveniente aceitação desse processo:
Eu, por exemplo, procurava ler os lábios, mas após uns 10 minutos os meus olhos começavam a arder, cansavam e eu desistia de prestar atenção nas aulas e ficava "olhandopara-a-parede”. Acho que se tivesse “diploma” para o total de horas "olhando-para-a-parede", eu bateria recorde por toda a minha vida escolar "inclusiva".

\section{Do preconceito do outro ao autopreconceito}

As identidades não se constroem no vazio. Ao contrário, estão relacionadas ao "conceito de representação, numa relação de interdependência, no sentido de que a construção da identidade se deve, em grande parte, a determinadas representações construídas, do mesmo modo que estas estão relacionadas às identidades “sustentadas” pelos sujeitos (Hall, 2000). Nesse sentido, entende-se que tanto a identidade como a diferença estão relacionadas às representações sociais.

A manutenção dos contrastes binários (normalidade/anormalidade, eficiência/deficiência,...) faz com que o surdo seja percebido como o oposto e negativo do ser ouvinte, não o aceitando enquanto uma experiência singular que constitui uma diferença específica (Skliar, 1998, p. 9). Essa lógica perversa naturaliza a homogeneização dos discursos que identificam o surdo por meio de características universais, a partir da marca da materialidade da surdez, como sendo constituídos por: "ritmos lentos de aprendizagem, inteligência primitiva, comportamentos agressivos, labilidade emocional, imaturidade afetiva e cognitiva, problemas nas relações interpessoais” (Schneider, 2006, p. 39).

Esses discursos globalizantes, sendo representações sociais que identificam o surdo como um ser anormal, incapaz, sem cultura própria, com uma língua pobre e uma maneira de ser esquisita, faz com que ele, principalmente quando privado de estar entre seus pares, assimile o olhar do ouvinte-opressor. Nesse sentido, é importante considerar que 95\% das crianças surdas são filhos de pais ouvintes, e a forma como é descoberta a surdez, por meio de exames audiológicos e imersos nos discursos clinico-terapêuticos, constitui- 
se em um dos importantes fatores da aceitação e perpetuação do rótulo estigmatizante do surdo como deficiente.

É incorporado ao ambiente familiar o poder das ciências médicas, como regime de verdade, que vai ao encontro do tipo de representação social dominante, que também identifica a surdez como uma condição de inferioridade, de incapacidade. Essas representações acabam por induzir o surdo a assimilar a forma como ele é percebido e narrado, levando-o também a perceber-se e narrar-se em oposição ao espelho ideal: lê-se ouvinte, para assimilar a imagem de ser deficiente, de menos valia.

$\mathrm{O}$ constrangimento de ter um filho visto como deficiente conduz a família, na maioria das vezes, a apresentar resistência ao uso da língua de sinais “símbolo por excelência da surdez”, da identidade individual e cultural do surdo (Ferreira Brito, 1993, p. 28, p. 54) - optando pelo método oralista, buscando a sua invisibilidade. Dessa forma, perpetua-se a obstinação no treinamento da palavra falada e da leitura desta como uma medida de normalização, desconsiderando os prejuízos à formação da identidade, ao desenvolvimento cognitivo e psíquico do sujeito surdo, fatos já conhecidos na literatura com abordagem socioantropológica, mas preteridos ante aos argumentos das ciências médicas.

A violência à qual os surdos são submetidos ao serem privados de sua língua natural levava-os a uma permanente sensação de isolamento, evidenciado no discurso de Laboritt (1994, apud Strobel, 2008b, p. 50), autora surda, quando afirma que privar os filhos da comunicação em língua de sinais é efetivar a

\footnotetext{
[...] exclusão da família, da casa onde todos falam sem se preocupar com você. Porque é preciso sempre pedir, puxar alguém pela manga ou pelo vestido para saber, um pouco, um pouquinho, daquilo que se passa em sua volta. Caso contrário, a vida é um filme mudo, sem legendas.
}

Em decorrência do isolamento, do sentimento de rejeição familiar, é comum o surdo reagir de forma apática ou agressiva - assim como qualquer criança ouvinte que fosse submetida à situação de violência similar. No entanto, isso é sempre interpretado, numa inversão perversa da lógica, como decorrente da surdez, e não pela violência à qual é submetido. Em relação a essa caracterização do comportamento do surdo como patológica, resgato a situação de uma linda menina surda, de sete anos, que conheci. Estava numa escola de surdos de Curitiba conversando com a professora da turma, enquanto acompanhava a harmonia com que os alunos interagiam através da língua de sinais. Nessa hora chegou a mãe de uma das alunas, que estava visivelmente feliz junto a seus colegas conversando em Libras. Vendo o comportamento da filha, a mãe fez o seguinte comentário: "Engraçado como aqui ela se comporta bem. Em casa ela não faz nada. Se não mandar tomar banho, não vai; fica só deitada no sofá assistindo à televisão. O pior é que às vezes ela começa a gritar, cada grito, que chega a doer os meus ouvidos!”. Perguntei se ela sabia a língua de sinais. Respondeu: "Não, não tive tempo ainda, tenho a casa para cuidar, muito trabalho”.

Nessa situação fica ilustrado o enorme preconceito em relação à surdez: a mãe recusa-se aprender a língua de sinais para se comunicar com sua própria filha. Submetida à segregação familiar que faz brotar um sentimento aniquilador decorrente da exclusão, a criança, em seu isolamento comunicativo, expressa em gritos a sua revolta, que é percebida como um quadro típico decorrente da surdez. A mãe apresenta uma reação de estranhamento ao comportamento harmonioso da menina na sala de aula. Os preconceitos estão tão assimilados que ela abdica do direito ao exercício da maternidade plena, eximindo-se também do seu dever maternal de promover uma condição digna de existência no meio familiar. Nesse sentido, vale ressaltar, como o psiquiatra surdo norueguês Terje Basilier, citado por Ferreira Brito (1993, p. 75):

\footnotetext{
[...] quando eu aceito a língua de outra pessoa, eu aceitei a pessoa [...]. Quando eu rejeito a língua, eu rejeitei a pessoa, porque a língua é parte de nós mesmos [...] Quando eu aceito a língua de sinais, eu aceito o surdo, e é importante ter sempre em mente que o surdo tem o direito de ser surdo.
} 
Além do exemplo referido, com o objetivo de enfatizar a perversidade dos preconceitos em relação à surdez, com a supremacia da valorização da palavra falada, que demonstra como introduzem uma sensação de menos valia, de isolamento, de perda, resgato o depoimento de Vilhalva (2004, p. 13): “Um papagaio fazia parte da família, eu ficava intrigada por que todos falavam mais com o papagaio do que comigo".

Também no depoimento de Karen Strobel (2008b, p. 40) está ilustrada claramente a extensão do prejuízo que a falta de feedback, comum entre as crianças ouvintes, acarreta à criança tanto psicológica quanto cognitivamente:

\begin{abstract}
Uma vez a empregada doméstica estava lavando o quintal no fundo de casa e eu ficava sentada observando a água suja de lama e sabão correndo até o bueiro. No meio desta sujeira estava um bicho estranho de mais ou menos uns seis centímetros que estava morto. Assustei-me porque o associava com o bicho que vi na televisão noutro dia, jacaré enorme que comia as pessoas e tive muitas noites de insônia com medo da existência deste bicho no nosso quintal e que viria me pegar e me comer. Só agora eu entendo que não era jacaré e sim simplesmente uma lagartixa. Não havia ninguém que me informasse sobre isso.
\end{abstract}

Como consequência dos processos segregacionistas e discriminatórios, de conviver permanentemente com o olhar preconceituoso do outro, é factível que o surdo desenvolva o auto-ódio, em “decorrência quase que direta do mecanismo de defesa chamado 'identificação com o agressor'” (Baibich, 2001, p. 19). Nesse processo estão os surdos que tentam se acomodar à sociedade ouvinte por sua autonegação, buscando identificar-se com o ouvinte tentando ser um deles. Os surdos identificados nesse processo, enquanto vítimas do preconceito, através do mimetismo ${ }^{6}$ de disfarce,

${ }^{6}$ O mecanismo de defesa denominado "mimetismo de disfarce" foi explicado pela professora Tânia Maria Baibich-Faria em 2007, em encontro de orientação com sua orientanda Edimara Soares, que utilizou essa expressão na abordagem do tema de sua dissertação de mestrado, da qual extrai a referência apresentada no texto. buscam um mecanismo de defesa. No entanto, esse mecanismo passa logo da defesa ao ataque, tornandose uma ameaça ao atacar a própria identidade, “dado que é impossível esconder ou tirar de si partes que são suas. Desta feita, este mimetismo [...] leva à ferida identitária que não cicatriza” (Soares, 2008, p. 13).

O auto-ódio que se efetiva através do processo da autonegação dos surdos que assimilam os preconceitos utilizando-se do mimetismo de disfarce coexiste com a incapacidade social imperante de relacionar-se com as diferenças. Nesse sentido, reafirmo o grande engodo que significa dizer "se o surdo falar português será aceito na sociedade ouvinte”, bem como o caráter conveniente da aceitação de que a leitura da palavra falada pode "substituir" a audição. Isso se torna evidente quando se verifica que até um desencontro de tonalidades de voz e o não-entendimento de algumas falas é suficiente para categorizar o surdo como um ser deficiente, tratá-lo como tal e tornar-se um empecilho à comunicação entre ambos.

Em relação a essa situação, faço referência novamente a minha vivência como surda: inúmeras vezes percebi o olhar incomodado em função do meu tom de voz, especialmente quando não faço uso da prótese auditiva, olhar esse acompanhado pela impaciência em relação ao meu não-entendimento de algumas das palavras faladas, como se fosse óbvio o que está sendo dito. E, ao buscar esclarecimentos sobre o que foi falado, é usual não os ter, com o argumento de que "não era nada", ou recebê-los de forma ridiculamente resumidas, ou, pior ainda, carregados já de um julgamento de valor, como se não fossemos capazes de abstraí-lo.

Em função desse "olhar” preconceituoso, quando ainda estava presa às amarras do ouvintismo, aceitava-o, sentindo-me extremamente constrangida. Indubitavelmente, no transcorrer da minha história de ensurdecimento, desde que tive detectada a perda auditiva, passei pelo processo de autonegação. Na tentativa de manter-me entre os ouvintes, tentando disfarçar a surdez, fazia uso da prótese auditiva praticamente 24 horas por dia, sem questionar seus reais benefícios, escondendo-a permanentemente. 
Nas circunstâncias em que não podia fazer uso da prótese, evitava falar ou, quando o fazia, buscava ser o mais sucinta possível. Dessa forma, utilizando-me do mimetismo de disfarce, alimentei o "ataque" à minha própria identidade, perdendo a autonomia sobre meu próprio corpo, tornando-o contido pelo uso do aparelho e pelos cuidados permanentes que exige, fingindo entender tudo que era falado, abdicando de meu direito de expressão, de participação; enfim, de viver plenamente.

Enquanto imersa no discurso clínico-terapêutico da surdez, assimilei a imagem de ser deficiente, de menos valia. Somente ao me libertar das amarras do ouvintismo é que pude avaliar a relação custobenefício do aparelho e aprender a fazer uso dele de forma consciente. Hoje o considero um intérprete temperamental de competência duvidosa; em situações desconhecidas, em que não sei se conseguirei contato próximo com quem esta falando e quando não posso contar com uma intérprete em Libras, constitui-se um recurso deficitário. Ao construir minha híbrida identidade surda, pude perceber a inversão da lógica perversa da situação de quem de fato deveria constranger-se, mantendo meu direito de sentir e expressar as emoções, assim como exigir o acesso pleno às informações, recusando os processos simplistas de tradução.

Nessa perspectiva, enfatizo o quanto a assimilação do ouvintismo como uma concepção de mundo que se propõe universal e superior, num esforço persistente de negação daquilo que é, acaba implicando uma identidade fracionada e a perda do direito ao exercício pleno da cidadania. Para ilustrar o sofrimento que esse processo de assimilação dos preconceitos gera, faço uma analogia com uma antiga fabula popular:

O corvo, insatisfeito com sua condição, admirava à distância a comunidade dos pombos - marcada pela elegância, pela cultura e pela beleza. Até que, certo dia, toma uma posição radical: pega uma lata de tinta branca e pinta-se inteiramente. Com essa nova roupagem, dirige-se ao pombal; lá chegando, é rapidamente identificado pelos pombos originais, que não permitem seu ingresso na sociedade. Decepcionado, decide voltar ao convívio de seus pares - os corvos. Lá chegando, todavia, a decepção se faz mais profunda; seus antigos irmãos não o reconhecem e o repudiam. Assim, sem ter o que tinha e não alcançando o que desejava, ficou o pobre corvo só, lamentando sua singular condição. (Souza e Silva, 2003, p. 140)

Essa fábula toca em uma questão crucial para os surdos: a pertença a um grupo minoritário, sobre o qual recaem inúmeros preconceitos que lhe atribuem menos valia. Por isso, o caminho da autonegação é uma possibilidade, uma tentativa de ser aceito. No entanto, assim como o corvo pintado de branco, o surdo é reconhecido: seja por sua fala adjetivada como "jeito surdo" de falar, pelo uso da prótese, pelo não-entendimento das palavras faladas, por seu tom de voz, por não ouvir ou, pelo menos, em níveis bem abaixo dos ouvintes. Dessa forma, a pretensa busca em ser aceito, através do mimetismo, tentando se igualar a estes, mesmo que use de todos os artifícios, como fingir que entende tudo o que é dito através da leitura da palavra falada, prática comum entre os surdos, seu disfarce se desmorona. E se, como o corvo branco, o surdo tentar ir ao encontro dos seus pares, carregando todos os preconceitos ouvintistas, o povo surdo também não o reconhece como um dos seus. Dessa forma, concordo com o fato de que a "assimilação, além de inútil em seu propósito, provoca sofrimento sem trégua, próprio ao processo de cisão identitária” (Baibich, 2001, p. 94).

\section{Considerações finais}

Episódios de preconceitos como os referidos são usuais no cotidiano dos surdos. A surdez foi construída historicamente a partir da diferença enquanto desvio da normalidade, numa abordagem patologizante. Apesar do novo discurso socioantropológico da surdez estar em voga, principalmente no meio acadêmico, esta é ainda uma escrita recente. Podemos encontrar muitas contradições inclusive entre alguns dos que fazem uso de um discurso que impressiona positivamente, contradições essas que também os surdos apresentam 
quando assimilam os preconceitos. Entre estes não posso deixar de fazer referência a mim mesma, como surda que também em muitos momentos me encontrei nas amarras do ouvintismo.

Para enfatizar a importância e a urgência de desconstruir as representações preconceituosas que envolvem o ser surdo, entre os quais a norma da fala e o mito da leitura da palavra falada, construindo outra narrativa na qual sejamos "vistos como sujeitos surdos e não sujeitos com surdez" (Lopes, 2007, p. 9), finalizo fazendo uso do discurso de Dalmo Dallari (apud Rulli Neto, 2002, p. 217-219, citado por Bolonhini, 2004, p. 286-289):

O preconceito acarreta a perda do respeito pela pessoa humana. [...] faz com que certas pessoas sejam estigmatizadas, sofrendo humilhações e violências, que podem ser impostas com sutileza ou relativo disfarce ou então de maneira escancarada, mas que em qualquer circunstância são negações do respeito devido à dignidade de todos os seres humanos. [...] O preconceito introduz a desigualdade. [...] Em consequência dos preconceitos, as pessoas direta ou indiretamente atingidas por eles são julgadas negativamente e colocadas em situação de inferioridade social [...] O preconceito estabelece e alimenta a discriminação. [...] promove a injustiça. (...) anulando a regra básica segundo a qual nenhuma pessoa vale mais do que a outra [...]. A par disso, onde atua o preconceito não importam os méritos, as aptidões, o valor moral e intelectual. [...] O preconceito cria superioridades e inferioridades.

\section{Referências bibliográficas}

AMARAL, Lígia Assumpção. Sobre crocodilos e avestruzes: falando de diferenças físicas, preconceitos e sua superação. In: AQUINO, Júlio Groppa. Diferenças e preconceito na escola: alternativas teóricas e práticas. São Paulo: Summus, 1998. p. 11-30.

BAIBICH, Tânia Maria. Fronteiras da identidade: o auto-ódio tropical. Curitiba: Moinho do Verbo, 2001.

BOLONHINI, Junior Roberto. Portadores de necessidades especiais: as principais prerrogativas e a legislação brasileira. São Paulo: Arx, 2004.
FERREIRA BRITO, Lucinda. Integração social \& educação de surdos. Rio de Janeiro: Babel, 1993.

FREUD, Sigmund. A psicopatologia da vida cotidiana. v. 6. Rio de Janeiro: Imago, 1976.

HALL, Stuart. A identidade cultural na pós-modernidade. Trad. Tomaz Silva e Guacira Louro. Rio de Janeiro, DP\&A, 2000.

LABORITT, Emmanuelle. $O$ vôo da gaivota. São Paulo: Best Seller, 1994.

LOPES, Maura Corcini. Surdez \& educação. Belo Horizonte: Autêntica, 2007.

LULKIN, Sérgio Andrés. O discurso moderno na educação dos surdos: práticas de controle do corpo e a expressão cultural amordaçada. In: SKLIAR, Carlos. A surdez: um olhar sobre as diferenças. Porto Alegre: Mediação, 1998. p. 33-50.

MACHADO, Paulo César. A política educacional de integração/inclusão: um olhar do egresso surdo. Florianópolis: Ed. UFSC, 2008.

PERLIN, Gladis. Prefácio. In: QUADROS, Ronice Muller de; PERLIN, Gladis (Orgs.). Estudos Surdos II. Petrópolis: Arara Azul, 2007. p. 9-13.

RULLI NETO, Antônio. Direitos do portador de necessidades especiais. São Paulo: Fiúza, 2002. p. 217-219.

SÁ, Nídia Regina Limeira de. Cultura, poder e educação de surdos. Manaus: Editora da Universidade Federal do Amazonas, 2002.

SACKS, Oliver. Vendo vozes: uma viagem ao mundo dos surdos. Trad. Teixeira Motta. São Paulo: Companhia das Letras, 1998. SCHNEIDER, Roseléia. Educação de surdos: Inclusão no ensino regular. Passo Fundo: Editora Universidade de Passo Fundo, 2006.

SCHWARCZ, Lilia Moritz. A questão racial brasileira vista por três professores: Florestan Fernandes, João Baptista Borges Pereira e Oracy Nogueira. Revista da USP, São Paulo: Coordenadoria de Comunicação Social da Universidade de São Paulo, n. 1, p. 168179, mar./maio 1989.

SKLIAR, Carlos. A educação para surdos entre a pedagogia especial e as políticas para as diferenças: desafios e possibilidades na educação bilíngue para surdos. Rio de Janeiro: Instituto Nacional de Educação de Surdos, 1998.

- Abordagens sócio-antropológicas em educação especial. In: SKLIAR, Carlos (Org.). Educação \& exclusão: abordagens sócio-antropológicas em educação especial. Porto Alegre: Mediação, 2000. p. 7-20.

SOARES, Edimara Gonçalves. Do quilombo à escola: os efeitos nefastos das violências sociais silenciadas. Dissertação (Mestrado 
em Educação) - Faculdade de Educação, Universidade Federal do Paraná, Curitiba, 2008.

SOUZAE SILVA, Jailson de. Por que uns e não outros?: caminhada de jovens pobres para a universidade. Rio de Janeiro: 7 Letras, 2003.

STARLING, Heloísa; SCHWARCZ, Lilia Moritz. Lendo canções e arriscando um refrão. Revista da USP, São Paulo: Coordenadoria de Comunicação Social da Universidade de São Paulo, n. 1, p. 210233, mar./maio 1989.

STROBEL, Karin. Surdos: vestígios culturais não registrados na história. Tese (Doutorado em Educação) - Faculdade de Educação, Universidade Federal de Santa Catarina, Florianópolis, 2008a.

. As imagens do outro sobre a cultura surda. Florianópolis: Ed. UFSC, 2008b.

SVARTHOLM, Kristina. Bilinguismo dos surdos. In: SKLIAR, Carlos (Org.). Atualidade da educação bilíngue para surdos. 2. v. Porto Alegre: Mediação, 1999. p. 15-24.

THOMA, Adriana da Silva; PELLANDA, Nize Maria Campos. As novas tecnologias como mediadoras nos processos de in/exclusão dos surdos na escola e na sociedade. Perspectiva - Revista do
Centro de Ciências da Educação, Florianópolis: Editora UFSC/ NUP/CED, v. 24, número especial, p. 119-138, jul./dez. 2006.

VILHALVA, Shirley. Despertar do silêncio. Petrópolis: Arara Azul, 2004. (Coleção Cultura e Diversidade.)

WRIGLEY, Oliver. Política da surdez. Washington: Gallaudet University Press, 1996.

SÍLVIA ANDREIS WITKOSKI é doutoranda no Programa de Pós-Graduação em Educação da Universidade Federal do Paraná (UFPR). Publicações recentes: Brincando com Portinari (2. ed. Rio de Janeiro: Ciência Moderna, 2006); O galo apaixonado (Rio de Janeiro: Ciência Moderna, 2006), A complexidade das relações inclusivas: um caso de uma aluna surda em um curso de Doutorado em Educação (Revista Iluminart, v. 1, n. 2, p. 108- 116, ago. 2009). Pesquisa em desenvolvimento: “O preconceito contra os alunos surdos: um grito”. Home-page: www.libraseliteratura. com.E-mail: silviaandreis@hotmail.com

Recebido em maio de 2009 Aprovado em junho de 2009 
occur and those that should be avoided. The purpose of this article is to contribute to the construction of conceptual tools that promote such an understanding.

Key words: e-learning; cybercitizen; modernity and technicism; human formation and democracy; isolated subject.

\section{El quien de la educación a distancia}

En un espacio corto de tiempo, la educación a distancia (EAD) pasó de un recurso marginal a un importante recurso de las políticas públicas y de las acciones empresariales. Hoy, no es posible no considerar el impacto que la introducción de la EAD on-line viene causando en nuestras formas corrientes de concebir y de practicar la educación y la comunicación. Sus más ardorosos defensores proclaman que las tecnologías de información y de comunicación están engendrando un nuevo tipo de sociedad y de humano. Sin embargo, se tiene la impresión de que el discurso de franca ruptura con el pasado resulta no sólo de la creencia severa en los medios tecnológicos, como de la imposibilidad de responder a las objeciones que podrian ser hechas. En este sentido, ahora se vuelve urgente investir en la profundidad teórica - que permitirá, tal vez, entender y calificar las rupturas que deban ser realizadas y aquella que deban ser evitadas. Es para la construcción de instrumentos conceptuales que favorezcan el esclarecimiento que el presente artículo pretende contribuir.

Palabras claves: EAD on-line; ciberciudadano; modernidad y tecnología; formación humana y democracia; sujeto aislado.
Sílvia Andreis Witkoski

\section{Surdez e preconceito: a norma da fala e o mito da leitura da palavra falada}

Falar sobre surdez e preconceito é narrar uma das interfaces do ser surdo. Dentre o imenso leque que o envolve, o artigo traz para discussão a norma da fala e o mito da leitura da palavra falada, por considerar que ambos legitimam uma série de práticas oralistas, afetando pejorativamente a construção da identidade do ser surdo e seu direito a uma comunicação e formação significativa. Em nome de uma pseudointegração entre surdos e ouvintes, mascaram-se os preconceitos em relação à surdez e aos surdos, ao implicitamente não aceitar sua diferença linguística, de percepção do mundo e forma de ser. Essa discussão é construída essencialmente a partir do resgate de muitas vivências dos próprios surdos, a fim de trazer à tona as suas nuanças, desvelando alguns dos discursos que legitimam esses preconceitos, buscando desnudar as implicações dolorosas que geram na vida dos surdos.

Palavras-chave: surdez; preconceito; Libras.

Deafness and prejudice: the norm of speech and the myth of lip reading To talk about deafness and prejudice is to describe one of the interfaces of being deaf. Among the many things that this involves, this article puts in discussion the norm of speech and the myth of "lip reading" because they both legitimate a series of oral practices, affecting negatively the identity of being deaf and the right to communicate in a meaningful way. In the name of a "pseudo-integration" of deaf with hearing people, prejudices in relation to deafness and the deaf are disguised, when implicitly not accepting their linguistic difference, their perception of the world and way of being. The discussion is built essentially on many experiences of deaf people themselves, in order to bring out the nuances, and in so doing, reveal some of the discourses which legitimize the prejudices, whilst seeking to lay bare the painful implications that these generate in the life of deaf people.

Key words: deafness; prejudice; sign language (Libras).

Sordera y prejuicio: la norma del habla y el mito de la lectura de la palabra hablada

Hablar sobre sordera y prejuicio es narrar una de las interfaces del ser sordo. En medio al inmenso abanico que lo envuelve, el artículo trae para la discusión la norma del habla y el mito de la lectura de la palabra hablada, por considerar que ambos legitiman una serie de prácticas orales, afectando peyorativamente la construcción de la identidad del ser sordo y su derecho a una comunicación y formación significativa. En nombre de una seudo integración entre sordos y oyentes, se disfrazan los prejuicios en relación a la sordera y a los sordos, al implicitamente no aceptar su diferencia lingüistica, de percepción del mundo y de su forma de ser. Esta discusión es construida esencialmente a partir del recate de muchas vivencias de los propios sordos, con el intuito de mostrar sus matices, descubriendo algunos de los discursos que legitiman esos prejuicios, buscando descubrir las implicaciones dolorosas que generan en la vida de los sordos. Palabras claves: sordera; prejuicio; Libras. 